be distinct realities, viz., Force and Energy. Further, he states that " the term 'potential' applied to Force or Energy means inactive, but capable of being called into action. Thus, if a weight be raised, a certain amount of energy is expended in raising it, and so long as the body is supported the energy expended in raising it remains potential in it, but when allowed to fall freely in vacus to the level from which it was raised, the body acquires exactly the amount of energy that was expended in raising it." This too is the view of Tyndall and Balfour Stewart. According to this doctrine, if I throw a stone upwards, say to the height of twenty feet, the energy expended is not lost, but gradually changed in form as the stone ascends. When the stone leaves the hand its energy is actual, at its maximum height it is potential. As a form of potential energy it is a kind of power existent in the stone, but unexerted until the stone begins to descend. According to the theory of conservation this unexerted power is not a reality which abides in the stone by virtue of its constitution, but a power that may be lost, and lost as quickly as it was gained. When the stone reaches the ground it possesses no energy beyond a portion of the heat generated by. the collision. The advocates of the conservation hypothesis tell us that the potential energy of the stone at its maximum height is a power to do work. We inquire what work, and are gravely assured that the stone has power to fall, which it could not do when it rested upon the ground ! Let us suppose that when the stone leaves my hand I was standing on a covered coal-pit two thousand feet deep, and that I remove the cover as the stone descends, if, as Mr. Brooke affirms, the Conservation of Energy is a fact, it follows that when the stone has fallen through twenty feet it will remain suspended over the pit. By its ascent it acquired power to fall only twenty feet, not two thousand and twenty feet. The metaphysicians, so much belaboured by Prof. Tait and other physicists, have ventured to think that the force of gravity has something to do with the fall of the stone. I have certainly found myself unable, even with the aid of the scientific imagination, to form an intelligible idea of the reality supposed to be symbolised by the term "potential ene:gy." The theory of the Conservation of Energy as now maintained by physicists is opposed in several respects to the doctrine of the conservation of force as held by Faraday. Stewart, Brooke, and orhers teach must explicitly that energy is not only constantly changing its form, but always shifting about from one portion of malter to another. If I mistake not, Faraday asserts the very opposite respecting force. He seems to teach that each material particle, into whatever combinations it may enter, retains all its original forces. "A particle of oxygen," he says, "is tver a particle of oxygen."

Mr. Brooke makes other admissions which are as inconsistent with the truth of the doctrine of the conservation as the one I have examined. These, however, I must leave for the present. I feel that the most satisfactory reply to $\mathrm{Mr}$. Brooke's strictures would be to quote here, with two trifling exceptions, the portion of my article which relates to the conservation of energy. Those exceptions I will now name. First, I withdraw what I have said respecting Mr. Brooke's view of the nature of latent heat. My sole reason for not in this connection quoting more was tinat I had assumed his perfect agreement with Prof. Tait. In this it seems I was wrong, since Mr. Brooke declares that he is unable to derive any definite idea from Prof. Tait's statement. I am sorry that Mr. Brooke should have supposed that the omission of the sentence named was due to a lack of literary honesty. I wonder that it did not occur to him that another and more charitable explanation was possible. Secondly, I was in error as to the weights employed by Dr. Joule in one of his experiments for determining the mechanical equivalent of heat. But this error relates merely to the form, not to the ultimate result of the experiment ; and consequently in no way invalidates my reasoning. Holding, as I do, that forces are both conserved and correlated, I feel no difficulty whatever in accepting the facts established by Dr. Joule. He avoids speculation regarding the nature of force in itself, and deals exclusively with its manifestations. Thus, his discovery of "the mechanical equivalent of heat" is the discovery of a relation between two classes of effects.

There is one misrepresentation in Mr. Brooke's review of my article I must here point out. $\mathrm{He}$ says, "the reviewer thus quaintly expresses the relations of force, energy, and motion :A given motion viewed as a cause is force, while the very same motion thought as an effect is energy." But this is not my doctrine. I am here dealing with the consequences of one of $\mathrm{Mr}$. Justice Grove's assumptions, viz., that if we attempt to analyse our conception of force, viewed as the cause of any perceived motion, we can get nothing beyond some antecedent motion. $\mathrm{Mr}$. Brooke complains that the misapplication of the term "force" has led to great confusion in physics. His own statements are nevertheless unsatisfactory, if not contradictory. $\mathrm{He}$ accepts the definition of force given by Faraday. But this socalled definition by Faraday is not definition at all. It merely tells us what force does, not what force is. Mr. Brooke adds that the definition "may perhaps with advantage be thus amplified :-Force is a mutual action between the atoms or molecules of matter."

But these molecular actions or motions are the effects of force, but not force itself. In no instance whatever can force be resolved into molecular motion. Mr. Brooke says, "One finds oneself occasionally brought by circumstances into an unwelcome generalisation. Thus the reviewer, speaking of the supporters of 'conservation' in the lump, says 'they talse it for granted that force is motion and nothing but motion.' This the writer entirely and absolutely denies." Will Mr. Brooke show that this denial is in harmony with his assertion that "force is a mutual action between the atoms or molecules of matter ?" I cannot. My reasons for rejecting the assumptions on which the doctrine of the conservation of energy rests are not noticed by Mr. Brooke. These assumptions I have shown belong to false and exploded metaphysics." A false philosophy of causation, it is easy to prove, has greatly retarded the progress of science.

I perceive that Mr. Brooke has used for reference one of a small number of copies of my article printed for private circulation. Unfortunately the paging does not correspond with that of the review. Had I only anticipated the pleasure of an encounter with Mr. Brooke, I would gladly have sent him the review itself. As Mr. Brooke is aware of what passed at a very recent meeting of the Victoria Institute, I cannot longer withhold my name.

Sale, near Manchester, June 26 JOHN MOORE

\section{Water Analysis}

IN NATURE for June 27, 1872, Mr. Wanklyn directs attention to the facts that his paper on water analysis appeared in I $\$ 67$, and that in I 868 he gave some absolute errors obtained with his process.

Mr. Wanklyn then proceeds to say :- "We have never said that distillation of albumin with alkaline permanganate converted the whole of the nitroyen of the albumin into ammonia. The assertion in your article is therefore untrue." Mr. Wanklyn's ideas of truth are probably peculiar, for if he will refer to his paper of June 20, 1867 (Chem. Soc. Jour. vol. v. N.S. p. 448), he will find the following:- "Direct experiments in which a known quantity of urea, gelatin, and albumin were taken, have shown that all the nitrogen in these substances is obtainable in the form of ammonia when they are subjecied to the treatment about to be described, and has disclosed the very singular fact that boiling with a caustic alkali liberates one-third of the nitrogen, both of albumin and of gelatin, in the form of ammonia, and that a subsequent boiling with permanganate of potash liberates the other two-thirds."

Not a word is said in the paper about carrying on the permanganate treatment to dryness, and the only reference to such treatment is on page 450 , where it is stated that boiling to dryness with potash alone causes the evolution of a "full third " of the nitrogen as ammonia.

\section{The Writer of the Article}

\section{Scintillation}

CAN any of your scientific correspondents tell me whether the following observation has been published, and, if so, where?

By very slight squinting, or (as suggested to me by a friend) by a slight pressure on one eye, we obtain two images of a star as viewed simultaneously from two stations a few inches apart. We made the experiment some nights ago, and could detect no relation whatever between the scintillations of the two. This seems to explain how little trace of the phenomenon remains when a telescope is used, for in that case we have a sort of integration performed over the whole aperture of the object-glass. G. H.

\section{To Entomologists}

How often is it that the entomologist has to regret the want of his net? The rare butterfly, by some curious perversity, is 